\title{
Detection of Ligands in Regions Anatomically Connected to Neurons Expressing the Eph Receptor Bsk: Potential Roles in Neuron-Target Interaction
}

\author{
Jian-Hua Zhang,, ${ }^{1}$ Douglas P. Cerretti, ${ }^{2}$ Tian Yu, ${ }^{1}$ John G. Flanagan, ${ }^{3}$ and Renping Zhou ${ }^{1}$ \\ ${ }^{1}$ Laboratory for Cancer Research, Department of Chemical Biology, College of Pharmacy, Rutgers University, Piscataway, \\ New Jersey 08855, 2Immunex Research and Development Corporation, Seattle, Washington 98101, and ${ }^{3}$ Department of \\ Cell Biology, Harvard Medical School, Boston, Massachusetts 02115
}

Neuron-target interaction is a key feature in the establishment of neuronal networks. However, the underlying mechanism remains unclear. We have shown that the time of target innervation, Bsk, an eph family receptor, is expressed at high levels in several brain regions including the hippocampus, olfactory bulb, and retina. To study whether the ligands are expressed in the target tissues, we investigated the expression of Bsk ligands using a ligand-affinity probe, Bsk-AP, which consisted of the extracellular domain of Bsk fused in frame with a human placental alkaline phosphatase. These analyses showed that the ligands were expressed at high levels in the developing septum, hypothalamus, olfactory neural epithelium, and tectum. In situ hybridization studies revealed that at least three different factors were respon- sible for the Bsk-AP binding. In the septum, Elf-1, Lerk3 (Efl-2), and AL-1/Lerk7 were transcribed. In the hypothalamus, AL-1/Lerk7 was the ligand detected by Bsk-AP. In the olfactory system, high levels of Lerk3 were detected in the sensory neurons. Both Elf-1 and AL-1/Lerk7 were present in the tectum. These ligand-positive areas are known to be anatomically connected to Bsk-expressing regions. These observations strongly suggest that Bsk and the ligands participate in neuron-target interactions in multiple systems and provide support for their involvement in topographic projection.

Key words: brain-specific kinase; growth factor receptor; eph family; alkaline phosphatase tagging; neuronal targeting; topographic projection
Neuron-target interaction is a key feature in the establishment of neuronal networks and plays a critical role in the development of topographic connections. Appropriate targeting by neurons requires that the guidance cues match terminals with specific cellular targets, a requirement accommodated by matching fixed tags on afferents and corresponding targets. Complementarity of molecular tags on afferents and targets was first postulated by Sperry in his chemoaffinity theory more than half a century ago (Sperry, 1943, 1963).

Only recently have specific candidate molecules been identified (Cheng et al., 1995; Drescher et al., 1995). Elf-1, a membraneanchored eph family ligand, and one of its putative receptors, Mek4, are expressed in complementary gradients in the chicken retina and tectum, respectively, fulfilling a long-standing prediction of Sperry's chemoaffinity theory (Cheng et al., 1995). Furthermore, an Elf-1-related molecule, the repulsive axonal guidance signal (RAGS), is expressed in the chicken tectum in an anteroposterior gradient and repels the growth of retinal axons (Drescher et al., 1995). The human homolog of RAGS, AL-1/ Lerk7, has been shown previously to be a ligand of the eph family receptor Rek7 (Winslow et al., 1995; Cerretti et al., 1996), a rat homolog of mouse Bsk (Zhou et al., 1994). These studies strongly implicate the eph family ligands and receptors in the development of topographic mapping.

Received April 19, 1996; revised Aug. 19, 1996; accepted Aug. 21, 1996.

This research was supported by National Science Foundation Grant IBN-9409930. We thank Y. Yue for critical comments on this manuscript.

Correspondence should be addressed to Renping Zhou, Laboratory for Cancer Research, College of Pharmacy, Rutgers University, Piscataway, NJ 08855.

Copyright (@) 1996 Society for Neuroscience $0270-6474 / 96 / 167182-11 \$ 05.00 / 0$
At least seven candidate ligands of the eph family have been isolated (Bartley et al., 1994; Beckmann et al., 1994; Cheng et al., 1994; Davis et al., 1994; Shao et al., 1994; Bergemann et al., 1995; Drescher et al., 1995; Kozlosky et al., 1995; Winslow et al., 1995). The ligands can be divided into two subfamilies, one with molecules anchored on the membrane through GPI anchors and the other with molecules containing a transmembrane domain. Four of the five ligands with GPI anchors-B61, Lerk3 (also named EFL-2; Davis et al., 1994), Elf-1, and AL-1/Lerk7-have been shown to bind to Bsk or its species homologs in vitro (Davis et al., 1994; Shao et al., 1995; Winslow et al., 1995; Gao et al., 1996). However, it is not known whether any of these molecules are accessible to Bsk in vivo, because no detailed in situ expression study has been published. Here we report studies on the expression of Bsk and its ligands during the development of mouse nervous system. Our studies suggest that Bsk may interact with multiple ligands in vivo and play important roles in the establishment and maintenance of projections in multiple systems.

\section{MATERIALS AND METHODS}

Animals. CD-1 mice from embryonic day 8 (E8) to E18 and postnatal day 1 (P1) through P180 were used in this study. At least two mice at each age were analyzed. The occurrence of a vaginal plug was defined as E1, and the day of birth was defined as P1. Embryos and brains were dissected under carbon dioxide anesthesia and immediately frozen on powdered dry ice. Coronal and sagittal sections of $14 \mu \mathrm{m}$ thickness were cut on a cryostat at $-20^{\circ} \mathrm{C}$ and thaw-mounted onto slides pretreated with triethoxy-3-aminopropyl silane (Sigma, St. Louis, MO; see LigandBinding Assay). These slides were then stored at $-80^{\circ} \mathrm{C}$ until use (up to 2 months).

Construction and expression of Bsk-AP. The affinity probe Bsk-AP was created as follows. An MroI restriction site was first introduced at the 

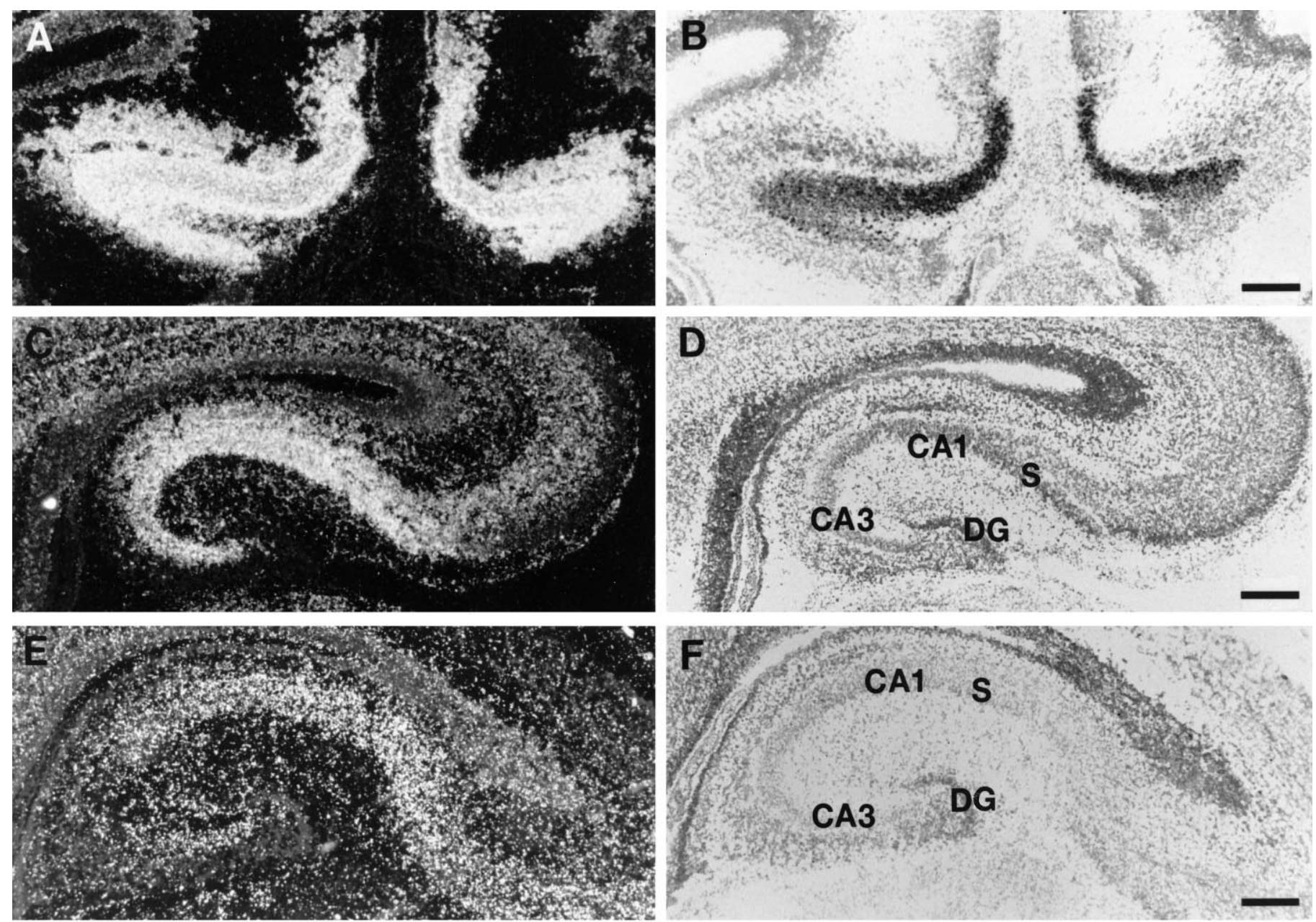

G

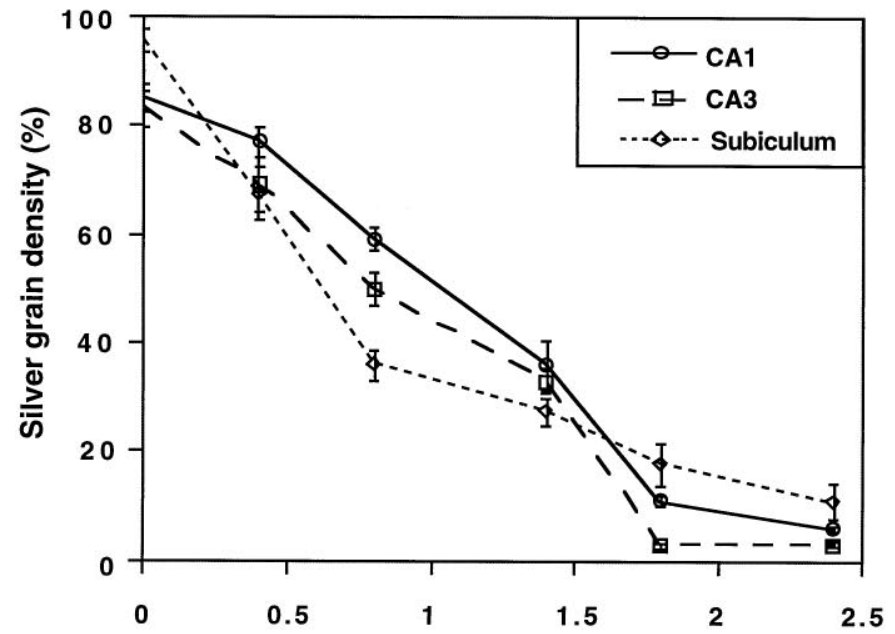

Figure 1. Differential Bsk expression along the mediolateral hippocampal axis. Bsk mRNA levels detected by in situ hybridization at different positions along the mediolateral axis are shown. $A, B$, Dark- and bright-field photomicrographs of a medial (septal) hippocampal section. $C, D$, Darkand bright-field photomicrographs of a section at an intermediate mediolateral level. $E, F$, Dark- and bright-field pictures of a lateral (temporal) hippocampal section. Slides shown here and in the following figures were counterstained with thionin. $G$, Quantitative analysis of Bsk in situ hybridization signals at different mediolateral hippocampal levels. $S$, Subiculum; $D G$, dentate gyrus. Scale bars, $200 \mu \mathrm{m}$.

junction of the extracellular and transmembrane domain by site-directed mutagenesis using an oligonucleotide 5'-GATCAAAGCCAGATTCCGGACATCATTGCAGTGTCAG-3' corresponding to nucleotide position 636-669 of Bsk (Zhou et al., 1994) with a GGA addition to create an MroI site. An EcoRI-MroI DNA fragment containing the entire coding region of the extracellular domain from the initiation codon to the last codon before the transmembrane domain of Bsk was ligated to a secreted form of human placental alkaline phosphatase in the APtag-1

Vector (Flanagan and Leder, 1990) using a BglII linker. The vector containing the fusion construct was cotransfected into National Institutes of Health-3T3 cells with pSV2neo plasmid containing the aminoglycoside phosphotransferase gene, which confers G418 resistance. The transfected cells were then selected with $400 \mu \mathrm{g} / \mathrm{ml} \mathrm{G} 418$ (Life Technologies, Gaithersburg, MD), and neo-resistant colonies were first screened for heatresistant alkaline phosphatase activity in the culture supernatant (Flanagan and Leder, 1990) and then for metabolically labeled Bsk-AP protein 

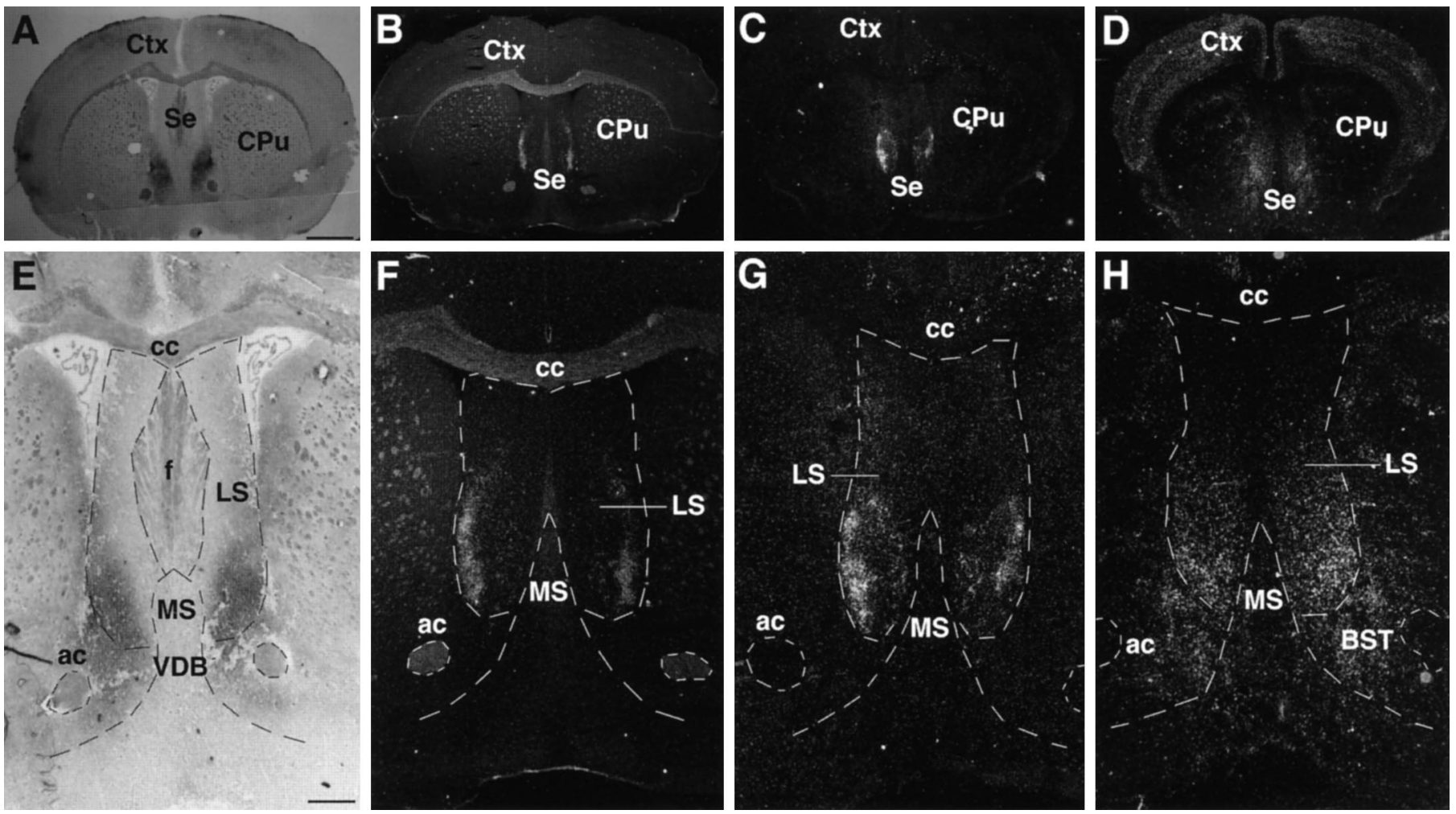

Figure 2. Expression of Bsk ligand(s) in the adult septum. $A$, E, Bsk-AP binding activity in the septum. $B, F$, Elf- 1 expression. $C, G$, Lerk3 expression $D, H, \mathrm{AL}-1 /$ Lerk7 expression. $A-D$, Coronal sections. $E-H$, Higher magnifications of the septal regions, showing that the expression of the ligands was restricted to the ventral lateral septum. $a c$, Anterior commissure; $c c$, corpus callosum; $f$, fornix; $B S T$, bed nucleus of the stria terminalis; $C p u$, caudate putamen; $C t x$, cerebral cortex; $L S$, lateral septum; $M S$, medial septum; Se, septum; $V D B$, vertical diagonal band; Scale bars: $A, 1.2 \mathrm{~mm} ; E, 0.6 \mathrm{~mm}$.

using immunoprecipitation with a monoclonal antibody against the human placental alkaline phosphatase (Medix Biotech). A protein with an expected molecular weight of $110 \mathrm{kDa}$ was detected only in the transfected cells in both the media and the cell lysates. The clone with the highest level of expression secreted $\sim 800 \mathrm{OD}$ units $\cdot \mathrm{ml}^{-1} \cdot \mathrm{hr}^{-1}$ heatresistant alkaline phosphatase activity.

To examine whether the secreted Bsk-AP was active in ligand binding, COS-7 cells transiently transfected with Elf-1, a putative ligand of Bsk, were stained with Bsk-AP. These experiments showed that Elf-1expressing cells, but not the cells transfected with the vector alone, stained positive with Bsk-AP, indicating that the fusion protein retained ligand-binding activity.

Ligand-binding assay. Frozen tissue sections of $14 \mu \mathrm{m}$ were mounted on slides coated with 3-aminopropyltrimethoxy silane (Sigma). Coated slides were prepared by washing first in acetone for $5 \mathrm{~min}$, followed with $100 \%$ ethanol. The slides were then dried at room temperature and coated by dipping in 2\% 3-aminopropyltrimethoxy silane in acetone for $15 \mathrm{sec}$. After coating, the slides were washed in acetone and distilled $\mathrm{H}_{2} \mathrm{O}$ and dried at room temperature overnight. Ligand detection was performed basically as described by Cheng et al. (1995). Briefly, frozen sections on the coated slides were incubated with Bsk-AP-containing tissue culture media for $90 \mathrm{~min}$ at room temperature and washed five times with HBSS (Sigma). The sections were then fixed for $30 \mathrm{sec}$ in $60 \%$ acetone, $3 \%$ formaldehyde, $20 \mathrm{~mm}$ HEPES, $\mathrm{pH} 7.5$, and washed twice with $150 \mathrm{~mm}$ $\mathrm{NaCl}, 20 \mathrm{~mm}$ HEPES, pH 7.5. Because the human placental alkaline phosphatase in the probe is heat-stable, the slides were heated at $65^{\circ} \mathrm{C}$ for 15 min to inactivate endogenous phosphatases. After heat inactivation, the slides were rinsed with $100 \mathrm{~mm}$ Tris- $\mathrm{HCl}, \mathrm{pH} 9.5,100 \mathrm{~mm} \mathrm{NaCl}$, and $5 \mathrm{mM} \mathrm{MgCl}_{2}$, and stained for $24 \mathrm{hr}$ in the same buffer containing $10 \mathrm{mM}$ L-homoarginine, $0.17 \mathrm{mg} / \mathrm{ml} \mathrm{BCIP}$, and $0.33 \mathrm{mg} / \mathrm{ml} \mathrm{NBT}$. After staining, the slides were mounted with coverslip and photographed.

In situ hybridization. In situ hybridization using Bsk and the ligand probes was performed as described previously (Zhou et al., 1994). Ligand probes are as described in the following sections.

Elf-1 probes. Two antisense oligonucleotide probes were used to detect Elf-1 expression. Elf-1-04, 5'-CTTGAAGCCTCGCTGCCGGTGGTC-
ACAGGAGGCGTGGCCCTCACC-3', corresponded to nucleotide position 283-328 in the Elf-1 coding region (Cheng et al., 1994). Elf-1-06, 5'-ACCTCATCCCTGTGGCTTGTTCCCTTCCCAGTGTCACCAGCAATGT-3', corresponded to nucleotide position 926-971 in the $3^{\prime}$-endnoncoding region of Elf-1 (Cheng et al., 1994). Neither oligonucleotide probe shared any significant homology with other eph family ligands or any other genes in the gene bank. The two probes gave similar patterns of hybridization. The corresponding sense probes were used as controls and gave no specific signals.

Lerk3 probes. Lerk3 is a mouse homolog of the human EFL-2/LERK3, a ligand isolated through binding to the rat homolog of Bsk, Ehk1 (Davis et al., 1994; Kozlosky et al., 1995). Lerk3 expression was detected with an antisense riboprobe and an oligonucleotide probe. For the generation of riboprobe, a mouse Lerk $3 \mathrm{cDNA}$ fragment was isolated using degenerate PCR primers from two conserved regions of the eph ligand family. The upstream primer, $5^{\prime}-\mathrm{A}(\mathrm{C}, \mathrm{T}) \mathrm{AT}(\mathrm{A}, \mathrm{C}, \mathrm{T}) \mathrm{TA}(\mathrm{C}, \mathrm{T}) \mathrm{TG}(\mathrm{C}, \mathrm{T}) \mathrm{CCI} \mathrm{CA}(\mathrm{C}, \mathrm{T})$ TA-3', corresponded to amino acid sequence DIY/ICPH, and the down stream primer, 5'-(T,G,A)AT(G,A)TA(G,A)TA(G,A)TA(T,C)TC(G,A)TG, corresponded to amino acid sequence HEYYYI. The 235-bplong Lerk3 was subcloned into the TA cloning vector (Invitrogen, San Diego, CA). Antisense probe and sense control were generated by SP6 or $\mathrm{T} 7$ in vitro transcription with $\left[{ }^{35} \mathrm{~S}\right] \mathrm{ATP}$ labeling. To confirm the results obtained with the riboprobe, an antisense oligonucleotide probe, 5'-GCGCTGTAACGCTGGAACTTCTCGGAGAACTTGATGGGGCTG-3', corresponded to nucleotide position 355-397 of Lerk3 cDNA sequence (Davis et al., 1994) was also used. Both the riboprobe and the oligonucleotide probe gave similar patterns of hybridization.

AL-1/Lerk7 probe. AL-1/LERK7 is a human homolog of the chicken RAGS, the repulsive axon guidance signal (Drescher et al., 1995; Winslow et al., 1995; Cerretti et al., 1996). Antisense riboprobe was transcribed from a $0.7 \mathrm{~kb}$ human AL-1/LERK7 cDNA cloned in pBluescript. The ligands of the eph family from different species generally share over $90 \%$ homology in the nucleotide level. The probe detects mouse Lerk7 specifically and does not hybridize with other eph family ligands as demonstrated by Southern blot analysis of mouse genomic DNA (D. 

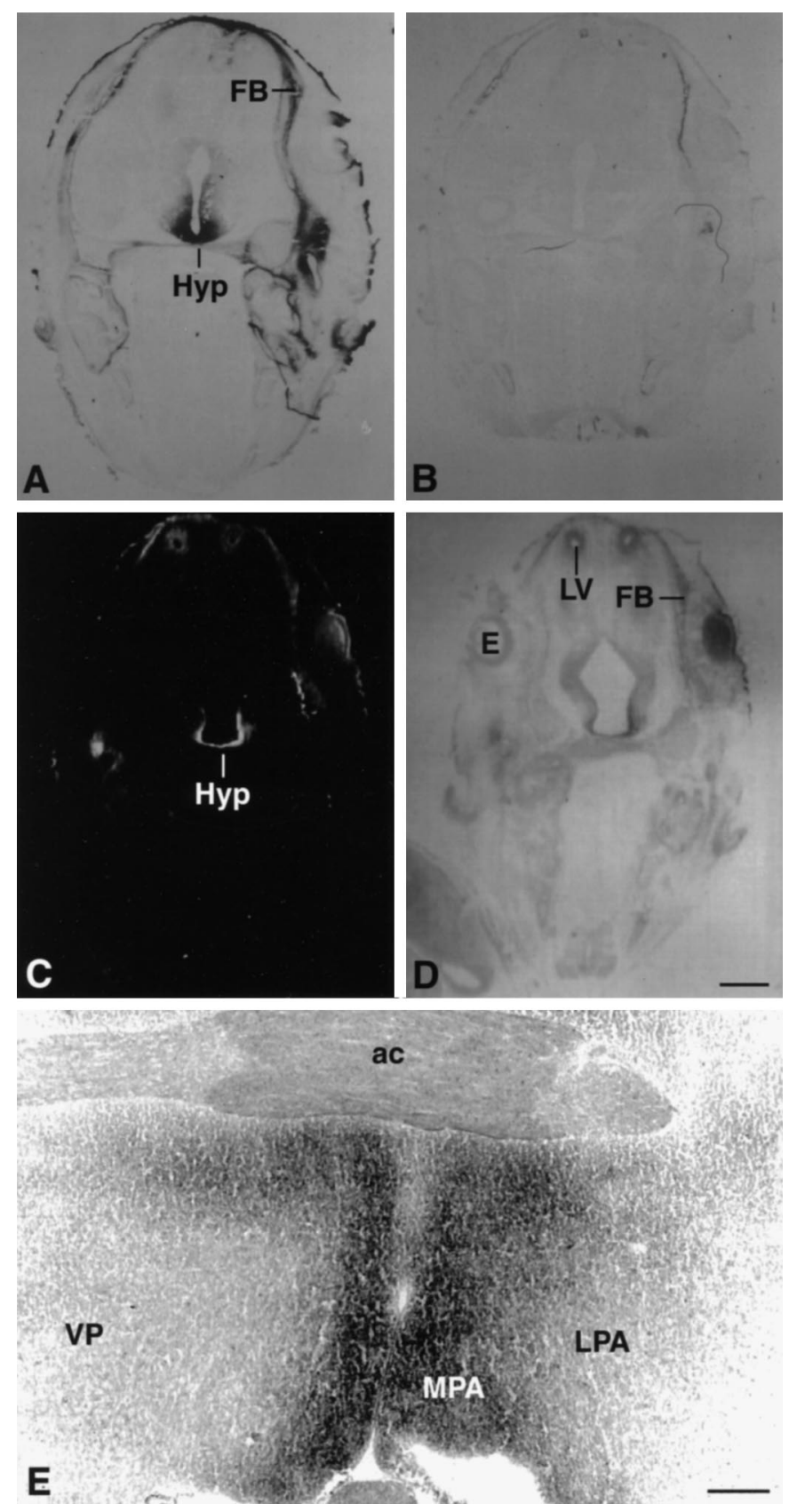

Figure 3. Expression of Bsk ligand in the hypothalamus. $A, B$, Coronal sections of E15 mouse embryos were stained with Bsk-AP $(A)$ or control alkaline phosphatase $(B) . C, D$, Dark- and bright-field photomicrographs of E15 mouse embryos hybridized to AL-1/Lerk7 cRNA probe. $E$, Coronal section through the preoptic area of an adult mouse brain stained with Bsk-AP. In situ hybridization of similar sections with AL-1/Lerk7 cRNA probe gave identical pattern of mRNA expression. $A c$, Anterior commissure; $E$, eye; $F B$, primordium of frontal bone; $H y p$, hypothalamus; $L V$, lateral ventricle; $L P A$, lateral preoptic area; $M P A$, medial preoptic area; $V P$, ventral pallidum. Scale bars: $D, 0.7 \mathrm{~mm} ; E, 0.2 \mathrm{~mm}$.

Cerretti, unpublished data). Sense probe was used as a control and revealed no specific binding.

Quantitation. Relative quantitative analysis of Bsk hybridization signals in the hippocampus and the olfactory bulb was performed using ImagePro image analysis software from Nikon. To avoid bias introduced by the variations of cell density in different regions, only areas within individual cells were quantitated for silver grain density, expressed as percent of area covered (area-fraction analysis).

\section{RESULTS}

To investigate the roles that the Eph family receptor Bsk may play during the development of the nervous system, we examined the expression of Bsk and its ligands in several systems during embryogenesis and postnatal life. Bsk mRNA was detected using antisense cRNA probes (Zhou et al., 1994). The ligands of Bsk were first examined with an affinity probe, Bsk-AP, the human placental alkaline phosphatase-tagged Bsk extracellular domain. Bsk-AP contains the entire extracellular domain of Bsk (for details, see Materials and Methods). Because of the promiscuity of the ligand-receptor interaction in the Eph family, Bsk-AP may bind to multiple ligands. To identify further the molecular nature of the ligands detected with Bsk-AP, cRNA and oligonucleotide probes against known ligands of the Eph family were used in in situ hybridization experiments. These studies indicate that Bsk and its ligands are expressed in distinct but synaptically connected regions of the brain, suggesting potential roles in neuron-target interactions.

\section{The expression of Bsk and its ligands in the hippocamposeptal system}

We have shown previously that Bsk is expressed at high levels in the hippocampus (Zhou et al., 1994). Careful examination of Bsk mRNA levels indicated that Bsk transcripts were distributed in a gradient (Fig. 1). The highest level of expression was found in the medial hippocampus, whereas the lowest level was found in the lateral hippocampus. Quantitation analysis revealed a steady decrease of Bsk mRNA levels from the medial to the lateral hippocampus in all of the CA fields, as well as in the subiculum (Fig. $1 G$ ). The hippocampal gradient was observed in E18 (Fig. 1), P7, $\mathrm{P} 14$, and adult mice (data not shown).

Analysis using Bsk-AP probe showed that the ligands were expressed in the hippocampal target tissues, the lateral septum, and the hypothalamus. In the septum, the ligands were detected in E18 (data not shown) as well as adult mouse brain (Fig. 2). The staining was limited to the ventral lateral septum with no signal in the dorsal lateral septum (Fig. 2A,E). In situ hybridization analyses indicated that at least three different ligands, Elf-1, Lerk3, and AL-1/Lerk7, were transcribed in this region. The expression patterns of Elf-1, Lerk3, and AL-1/Lerk7 were examined throughout the rostral-caudal positions, and Figure 2 shows representative patterns of expression at comparable levels of the septum. Elf-1 (Fig. 2B,F) and Lerk3 (Fig. 2C,G) mRNAs were located in relatively narrow strips along the lateral edge of the septum, defined by the lateral ventricles. The ventral lateral septum showed higher expression of both Elf-1 and Lerk3 than the dorsal lateral septum. AL-1/Lerk7 was also detected in the ventral lateral septum (Fig. 2D,H). However, AL-1/Lerk7 mRNA was distributed in a diffused manner. These patterns of expression were maintained in different rostrocaudal levels. Thus, although there were three different ligands expressed in the ventral lateral septum, the specific location of these ligands were different, suggesting a combinatorial mechanism for the specification of the septal target field.

In addition to the septal regions, an area in the diencephalon also showed intense Bsk-AP binding. Analysis of Bsk-AP binding on the coronal sections revealed that the diencephalon expression was in hypothalamus (Fig. $3 A$ ). The expression in the hypothalamus was observed as early as E12 and persisted through late embryogenesis and adult (Fig. 3). The highest expression was limited to the medial hypothalamus, with decreasing levels toward the lateral regions (Fig. $3 E$ ). The level of expression was highest 

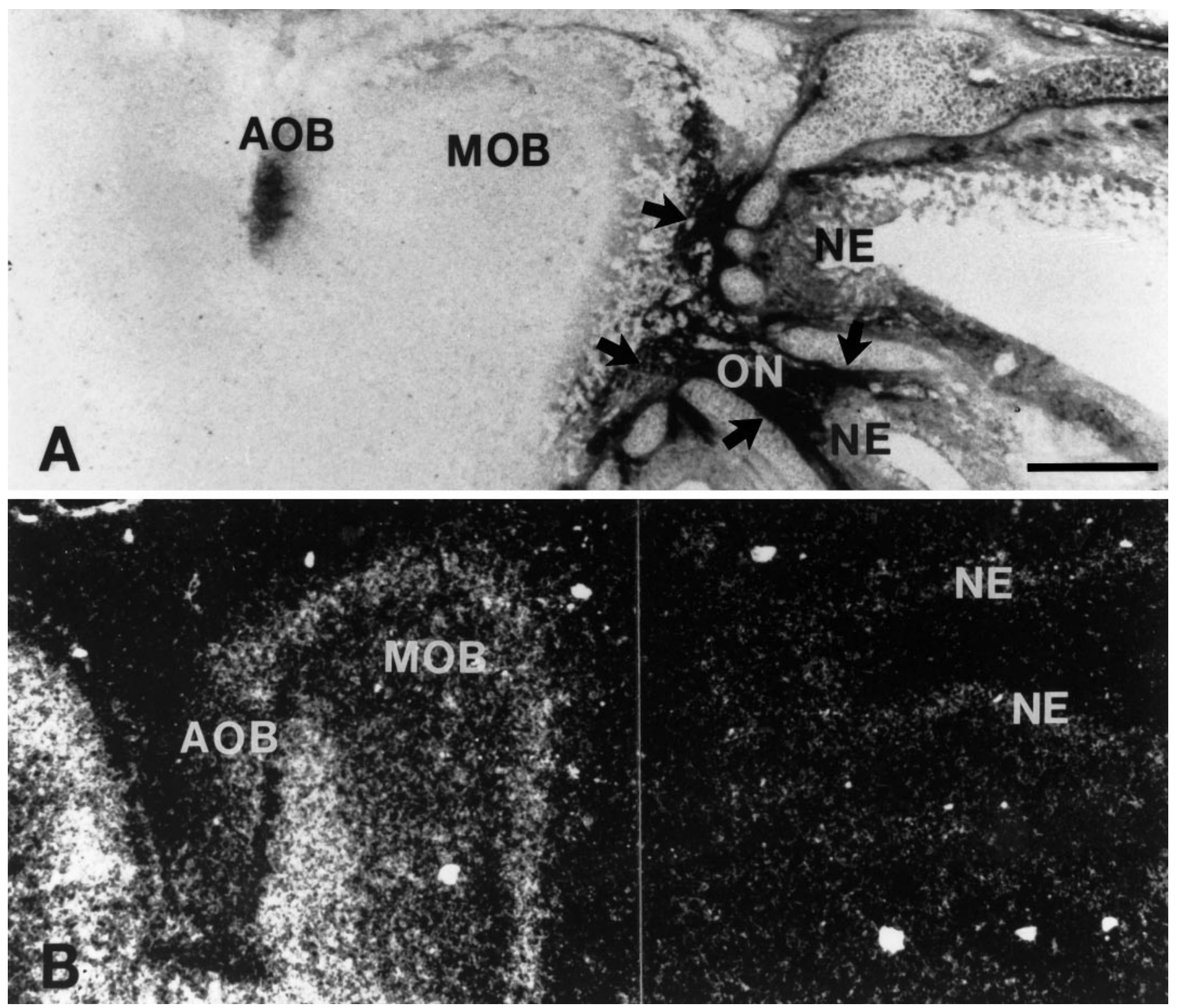

Figure 4. Complementary expression of Bsk and ligand(s) in the E18 olfactory system. $A$, Photomicrograph of a sagittal section of the olfactory bulb and nasal epithelium stained with Bsk-AP (areas indicated by arrows). $B$, Bsk receptor expression detected by in situ hybridization in a similar section as in $A$. $A O B$, Accessory olfactory bulb; $M O B$, main olfactory bulb; $N E$, nasal epithelium; $O N$ olfactory nerve. Scale bar, $0.5 \mathrm{~mm}$.

in the rostral end of the hypothalamus (preoptic area) (Fig. $3 E$ ) and decreased to very low levels toward the caudal end (mamillary nuclei; data not shown).

In situ analysis revealed that AL-1/Lerk7 was responsible for the ligand expression in the hypothalamus (Fig. $3 C$ ). Very high levels of AL-1/Lerk7 expression were detected in embryonic hypothalamus (Fig. 3C). However, the expression decreased to moderate levels in adult hypothalamus (data not shown). The distribution of AL-1/Lerk7 in both the embryonic and the adult hypothalamus is identical to that of Bsk-AP staining.

AL-1/Lerk7 expression was also detected, in addition to the septum and hypothalamus, in many other regions. Significant expression was found in the tectum (Fig. 8), motor cortex, thalamus, and deep cerebellar nuclei, whereas no expression was detected in the hippocampus (data not shown).

\section{Complementary expression of Bsk and its ligands in the olfactory system}

Examination of Bsk and its ligand in the olfactory system also showed a complementary pattern of expression (Fig. 4). Bsk ligand was detected in the nasal epithelium, the olfactory nerve, and the olfactory bulb (Fig. $4 A$ ). In the olfactory bulb, ligand staining was found to be along the edge of the bulb (Fig. $4 A$; see also Fig. 5A). In situ hybridization using an antisense Bsk receptor probe revealed no signals in the nasal epithelium (Fig. 4B). However, a high level of Bsk was detected in the neurons of the main olfactory bulb (Fig. 4B). Examination of coronal sections of adult olfactory bulb stained with Bsk-AP showed that the ligand expression in the olfactory bulb was located in the olfactory nerve and in the glomeruli (Fig. $5 A, C$ ), whereas Bsk receptor was found in the mitral and granule cells (Fig. 5B,D). However, not all of the 

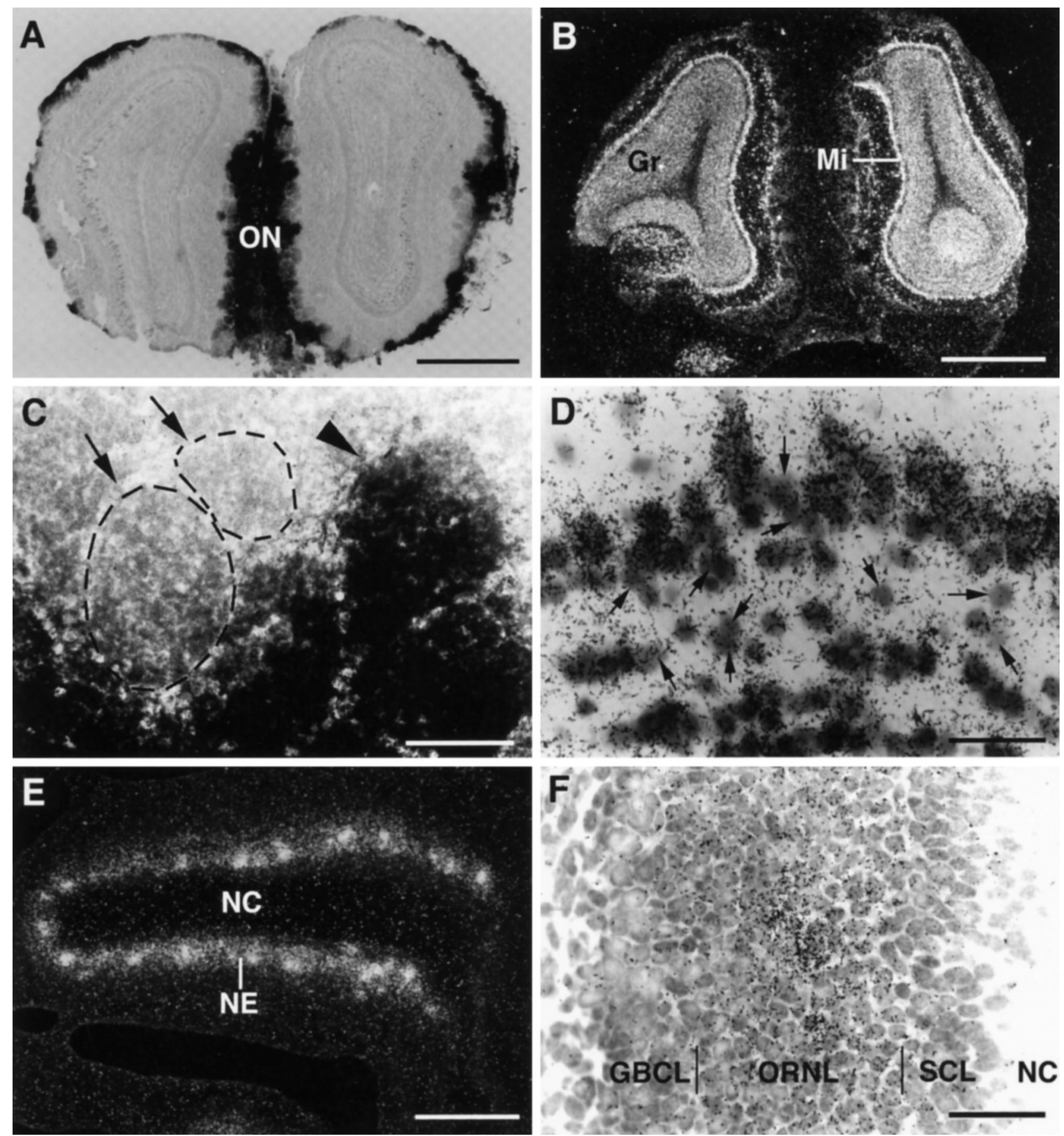

Figure 5. Differential distribution of Bsk and Lerk3 in the mouse olfactory system. A, Bsk-AP staining of a coronal section through the adult olfactory bulb. $B$, Detection of Bsk receptor by in situ hybridization in the adult olfactory bulb. Note the complementary patterns of ligand and receptor expression. $C$, A higher magnification of Bsk-AP-stained adult glomerular structures, showing that ligand-positive (arrowhead) and ligand-negative glomeruli (arrow, circled). D, Higher magnification of Bsk in situ hybridization signals in the adult olfactory bulb, showing that the expression in the mitral and granular cells is not uniform. Numerous Bsk-negative cells were clearly visible (arrows). The average silver grain density (\% area of cells covered) of the Bsk-positive cells was $11.3 \pm 1.6$ compared to $2 \pm 0.27$ for the Bsk-negative cells and $1.9 \pm 0.17$ for the background level. $E, F$, Low and high magnification of Lerk 3 in situ hybridization signals in P3 olfactory nasal epithelium, showing an uneven distribution. $G B C L$, Globose basal cell layer; $G r$, granule cell layer; $M i$, mitral cell layer; $N C$, nasal cavity; $N E$, nasal epithelium; $O N$, olfactory nerve; $O R N L$, olfactory receptor neuron layer; $S C L$, sustentacular cell layer. Scale bars: $A, B, 1.76 \mathrm{~mm} ; C, 100 \mu \mathrm{m} ; E, 200 \mu \mathrm{m} ; D, F, 25 \mu \mathrm{m}$.

glomeruli expressed the ligand (Fig. 5C). In situ hybridization analyses revealed that Lerk3 was transcribed at high levels in the olfactory nasal epithelium (Fig. 5E), with only low levels elsewhere (data not shown). Furthermore, Lerk3 was expressed in only a subpopulation of odor receptor neurons (Fig. 5E,F), con- sistent with the presence of ligand-negative glomeruli detected by Bsk-AP staining (Fig. 5C). Similarly, only a portion of the olfactory mitral cells expressed high levels of Bsk receptor (Fig. $5 D$ ). The expression of Bsk and Lerk3 was found in the olfactory system as early as E13 and persisted through late embryogenesis 

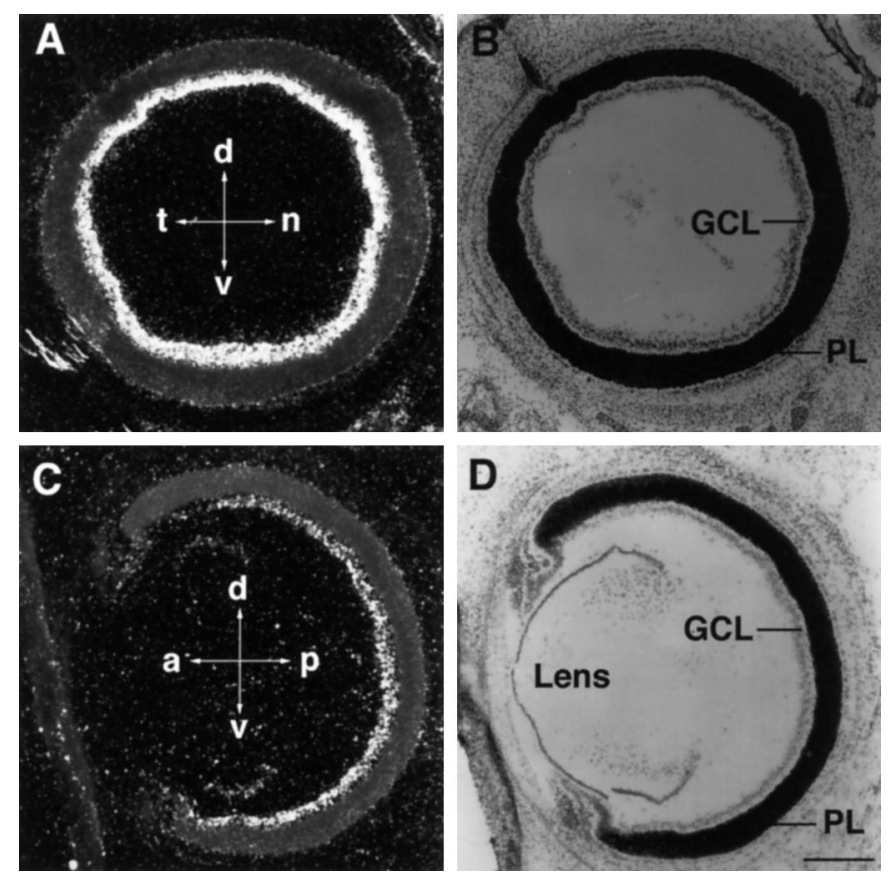

Figure 6. Bsk expression in the retina. $A, B$, Dark- and bright-field photomicrographs of a coronal view of a E18 mouse retina. $C, D$, Darkand bright-field photomicrographs of a sagittal view of a E18 mouse retina. The signal intensity in $A$ and $C$ are not comparable because the results were obtained in separate experiments. $a$, Anterior; $p$, posterior; $d$, dorsal; $v$, ventral; $t$, temporal; $n$, nasal; $G C L$, ganglion cell layer; $P L$, plexiform layer. Scale bar, $320 \mu \mathrm{m}$.

(Fig. 4) and adult (Fig. 5 and data not shown). No Elf-1 and only low levels of AL-1/Lerk7 expression were detected in this region (data not shown). These observations further demonstrate that although Bsk and its ligands were expressed in distinct neuronal populations, the ligand- and Bsk-positive regions are synaptically connected, suggesting an important role of these ligand and receptor molecules in neuron-target interaction.

\section{Expression of Bsk and its ligands in the retinotectal system}

Bsk mRNA was detected in E12 retina, the earliest stage examined. The expression persisted in late embryogenesis (Fig. 6) and in early postnatal mice (data not shown). Examination of Bsk in situ signals revealed no apparent differences in mRNA levels between the nasal and temporal, dorsal and ventral, or anterior and posterior retina, in contrast to cek4 and cek5 (Cheng et al., 1995; Holash and Pasquale, 1995).

Expression of the ligands was detected in the mesencephalon, the presumptive midbrain, at E10 using Bsk-AP probe (Fig. $7 A, B)$. By E13, high levels of Bsk-AP-binding activity were detected in the tectum, the target tissue of retina ganglion cells (Fig. $7 C, D)$. The binding activity in the tectum was maintained at E15 (Fig. $7 E$ ) and E18 but decreased to very low levels in the adult (data not shown). The highest level was in the posterior tectum, and the expression level appeared to form an anterior-posterior gradient (Fig. 7C,E).

In situ hybridization with Elf-1 antisense oligonucleotide probes revealed that Elf-1 was transcribed in the tectum (Fig. $8 A, B$ ). The tectal expression of Elf-1 was detected in E11 and persisted in E16 (Fig. 8A,B), E18, and P3 (data not shown). Elf-1 mRNA decreased to very low levels in P7 and was undetectable in P14 and adult midbrain (data not shown). Elf-1 expression was detected in all layers of the neuroepithelium (Fig. $8 A, B$ ).

In addition to Elf-1, high levels of AL-1/Lerk7 mRNA were detected in the tectum (Fig. 8C,D). Examination of embryos of different stages indicated that, similar to Elf-1, AL-1/Lerk7 mRNA was transcribed in the tectum from E11, the earliest stage examined, through P7, but not in P14 and adult (data not shown). However, AL-1/Lerk7 expression was restricted to a more posterior region of tectum than Elf-1 (Fig. $8 C, D$ ). In E16 tectum, Elf-1 was found in the region corresponding to the superior colliculus and AL-1/Lerk7 was detected in the inferior colliculus (Fig. 8). Furthermore, AL-1/Lerk7 mRNA was found mainly in the ventricular cells, in contrast to Elf-1, which was more evenly distributed in all layers of the tectal neuroepithelium (Fig. 8). Similar patterns of mRNA distribution of Elf-1 and AL-1/Lerk7 were observed in sections of both the medial and the lateral tectum.

\section{DISCUSSION}

We have shown that Bsk and its ligands are expressed in distinct but synaptically connected regions in several neural circuits. These findings suggest that Bsk and its ligands may play important roles in mediating neuron-target interaction in multiple systems. In addition, our studies indicate that Bsk may interact with multiple ligands in vivo, consistent with promiscuous binding of eph family ligands to receptors in vitro.

\section{Specification of target fields by combinations of multiple Eph ligands}

We have shown in this study that three different ligands of the eph family were detected by Bsk-AP binding. The intense ligand staining in the septum, hypothalamus, nasal epithelium, and tectum corresponds to the high mRNA expression of multiple ligands in these regions (Table 1). Because the ligands were expressed in regions with axonal connections to Bsk-positive neurons, the interaction between Bsk and these ligands may occur in vivo. This is consistent with in vitro binding studies showing that all three ligands interact with Bsk or its species homologs (Davis et al., 1994; Shao et al., 1995; Winslow et al., 1995; Gao et al., 1996).

The three ligands show distinct yet overlapping patterns of expression (Table 1). In the septum, all three ligands are expressed in the ventral lateral area. However, the expression patterns are different. Elf-1 and Lerk3 appear to be in a narrow strip along the lateral edge of the septum (Fig. 2), whereas AL-1/Lerk7 was expressed in a diffused manner all over the ventral lateral septum (Fig. 2). Dorsoventral differences in expression levels are evident in the lateral septum for all three ligands. When the expression pattern of the three ligands are overlapped, a twodimensional gradient, that is, a dorsomedial-to-lateroventral gradient can be perceived (Fig. $9 A$, bottom panel). In the tectum, both AL-1/Lerk7 and Elf-1 are expressed. However, AL-1/Lerk7 was detected in a more posterior position than Elf-1 (Fig. 8), suggesting that the two ligands together form a bigger and continuous gradient as detected by Bsk-AP (Fig. 7C,E). Thus, these results suggest that combinations of different ligands specify the spatial information for hippocamposeptal and retinotectal projections.

\section{The expression patterns of Bsk and the ligands in the hippocamposeptal system are consistent with a function in the topographic projection}

Hippocampal neurons project topographically to the lateral septum (Swanson and Cowan, 1977; Swanson et al., 1987). Neurons along the mediolateral axis project to the lateral septum along the mediodorsal-to-lateroventral axis. Thus, medial hippocampal neu- 

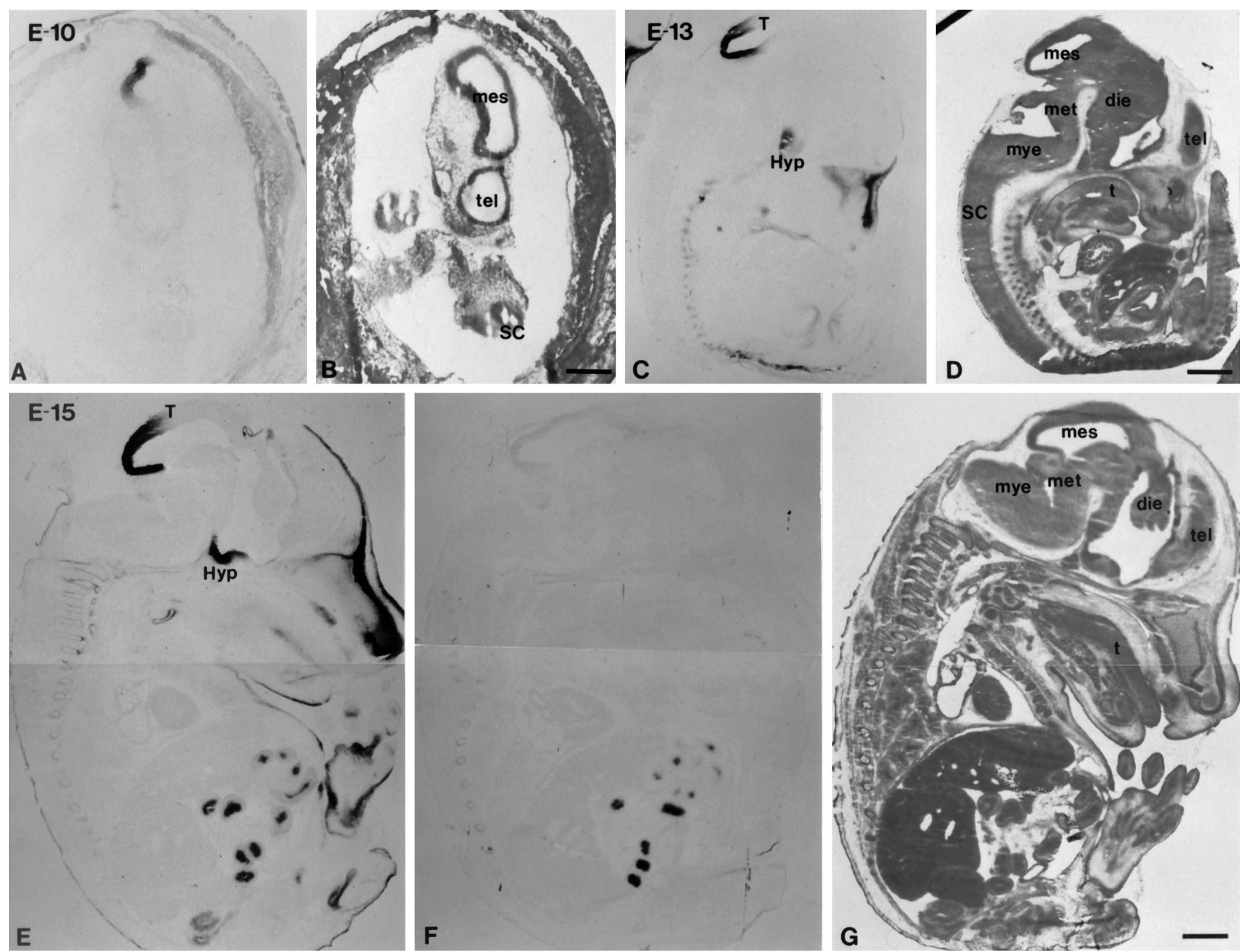

Figure 7. Sagittal views of expression of Bsk ligand(s) during mouse embryogenesis. Neighboring sagittal sections from E10 $(A, B)$, E13 $(C, D)$, and E15 $(E-G)$ embryos were stained with Bsk-AP $(A, C, E)$ or $\mathrm{H} \& \mathrm{E}(B, D, G)$. Human placental alkaline phosphatase not fused to Bsk was used in parallel sections as a control $(F)$. In E10 and E13 embryos, no specific staining was observed in control sections. In E15 $(F)$ and E18 embryos, endogenous heat-resistant alkaline phosphatase activity was detected only in the intestine. die, Diencephalon; mes, mesencephalon; met, metencephalon; mye, myelencephalon; tel, telencephalon; $t$, tongue; Hyp, hypothalamus; $S C$, spinal cord; $T$, tectum; Scale bars: $B, 1 \mathrm{~mm} ; D, G, 2 \mathrm{~mm}$.

Table 1. Expression of Bsk ligands in developing mouse nervous system

\begin{tabular}{lllll} 
& \multirow{2}{*}{$\begin{array}{l}\text { Ligand } \\
\text { protein }\end{array}$} & \multicolumn{3}{l}{ Ligand mRNA } \\
\cline { 3 - 5 } & Elf-1 & Lerk3 & AL-1/Lerk7 \\
\hline Superior colliculus & ++ & ++ & 0 & 0 \\
Inferior colliculus & +++ & 0 & 0 & +++ \\
Lateral septum & ++ & ++ & ++ & ++ \\
Hypothalamus & +++ & 0 & 0 & ++ \\
Thalamus & 0 & 0 & 0 & + \\
Hippocampus & 0 & 0 & + & 0 \\
Nasal neuroepithelium & +++ & 0 & +++ & + \\
Cerebral cortex & + & + & + & + \\
Spinal cord & + & + & + & + \\
\hline
\end{tabular}

rons, which express high levels of Bsk, project to the mediodorsal lateral septum where no ligands are expressed, whereas lateral hippocampal neurons, which do not express Bsk receptor, send their axons to the ventral lateral septum which expresses high levels of ligands (Fig. 9A). Thus, Bsk and the ligands are expressed in a complementary (opposing) manner in projecting and target fields in the hippocamposeptal system. In vitro studies revealed that growth of neurites from medial hippocampal neurons is inhibited by at least one of the ligands, Elf-1, whereas the growth of lateral hippocampal neurites is not affected, suggesting that the ligands in the ventral lateral septum serve to exclude the septal hippocampal axons from this region (Gao et al., 1996). The topographic relations and the complementary expression of Bsk receptor and its ligands in the hippocamposeptal system are summarized in Figure $9 A$.

The ingrowth of the hippocampal axons to the lateral septum occurs from E21 to P14 in the rat (Linke et al., 1995). Although the exact timing of the development of the topographic order is not known, it is probably during the early postnatal period. Bsk and its ligands can be detected in gradients in the hippocampus and septum regions, respectively, from E18 through adult. Thus, the time period of expression of Bsk and its ligands overlaps with that of development of the topographic projection. The hip- 

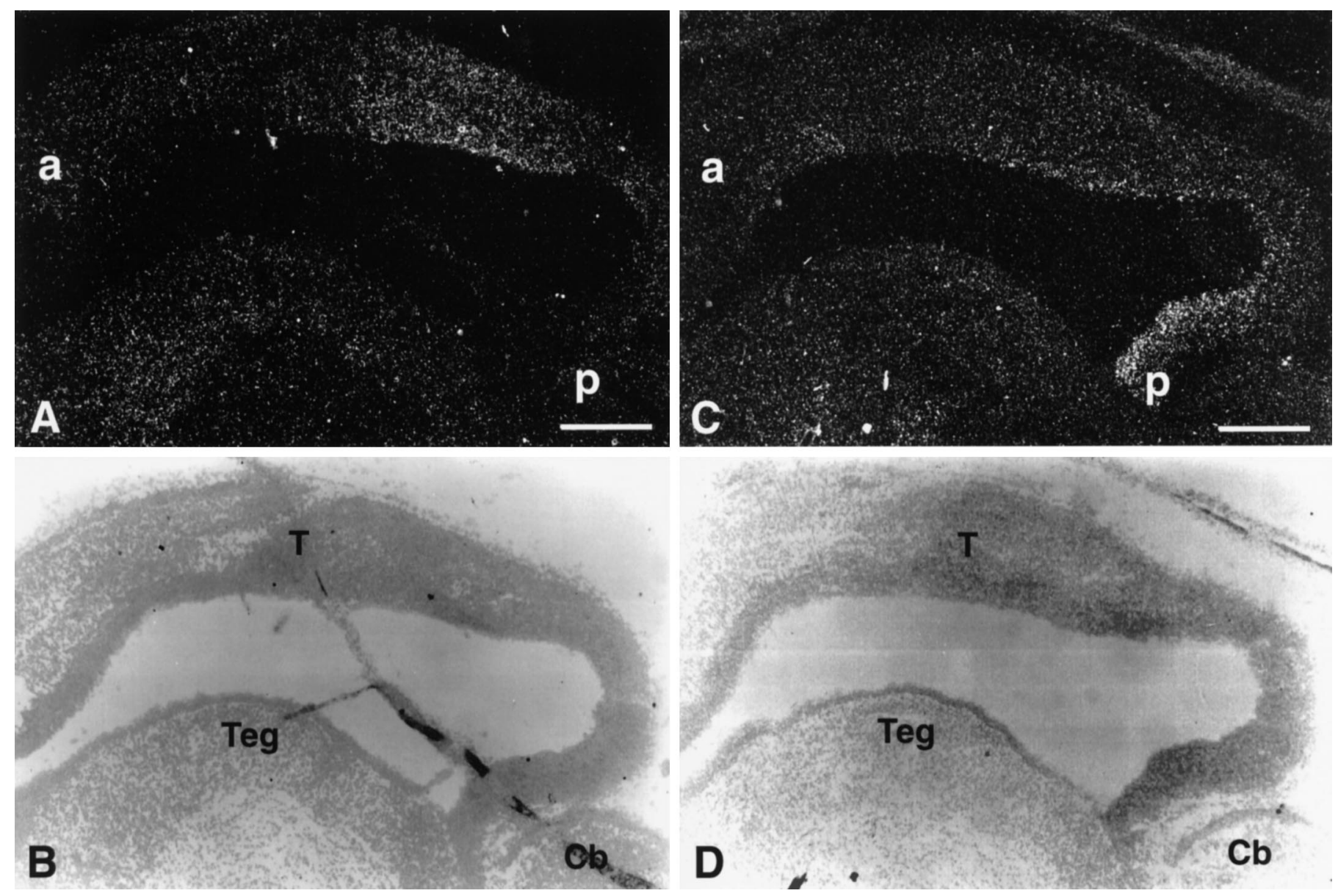

Figure 8. Expression of Elf-1 and AL-1/Lerk7 in E16 tectum. $A, B$, Dark- and bright-field photomicrographs of a parasagittal section through the tectum hybridized with Elf-1 probe. $C, D$, Dark- and bright-field views of a serial section to $A$ and $B$, hybridized with a AL-1/Lerk7 probe. $a$, Anterior tectum; $p$, posterior tectum; $C b$, cerebellum; $T$, tectum; Teg, tegmentum. Scale bar: $250 \mu \mathrm{m}$.

pocampus is well known for structural remodeling in the adult. The presence of expression of Bsk and its ligands in the adult hippocamposeptal system further suggests that they may also play a role in synaptic plasticity.

High levels of ligand expression were also detected in the hypothalamus. The ligand is expressed at higher levels in the rostral (the preoptic) region and at lower levels toward the caudal (the mamillary nuclei) end. The hypothalamus receives input from many regions of the brain (Swanson, 1987). Several of these regions, such as the subiculum and amygdala, express high levels of Bsk (Zhou et al., 1994). Because dorsal subiculum (high Bsk expression) projects to the caudal hypothalamus (low ligand), and the ventral subiculum (low Bsk) projects to the rostral hypothalamus (high ligand) (Swanson and Cowan, 1975), the pattern of projection with respect to the expression of Bsk and its ligand is similar to the hippocamposeptal system.

\section{Role of Bsk and its ligands in neuron-target interaction in the olfactory system}

The complementary expression of the ligands and Bsk in the olfactory system provides strong support for their roles in neurontarget interaction, because olfactory sensory neurons project solely into the olfactory bulb. Olfactory receptor neurons project to the mitral cells and tufted cells in the olfactory bulb, and the neurons form synapses in the glomeruli (Graziadei, 1990; Shep- herd, 1994). The first synaptic contacts of olfactory axons with dendritic processes of mitral cells in the rat olfactory bulb occur at E18. Glomerular formation is initiated by E20. Mitral cells initially grow multiple dendrites of uniform diameter, and individual mitral cells innervate multiple adjacent glomeruli. The dendrites are then remodeled so that only one primary dendrite is maintained for each mitral cell, innervating one glomerulus (Malun and Brunjes, 1996). The remodeling process is completed by $\mathrm{P} 10$ (Malun and Brunjes, 1996).

The expression of Bsk and its ligands was found in the olfactory system as early as E13 and persists through embryogenesis and into the adult. The expression of Lerk 3 and Bsk in the olfactory system at the time of glomerular formation is consistent with their roles in the selection of glomeruli by mitral cells. The interaction between Bsk and Lerk3 may cause the retraction of Bsk-positive dendrites from ligand-positive glomeruli during remodeling and thus define different types of synapses (Fig. 9B). This model is consistent with the inhibitory functions of Eph ligands observed in the hippocamposeptal and retinotectal systems, and it provides a potential mechanism for target selection by odor receptor and mitral cells. The expression of ligands in the projecting neurons and the receptor in the target neurons, contrary to the hippocamposeptal system, suggests that Bsk and the ligands may function not only in a retrograde but also in an anterograde manner. 
A
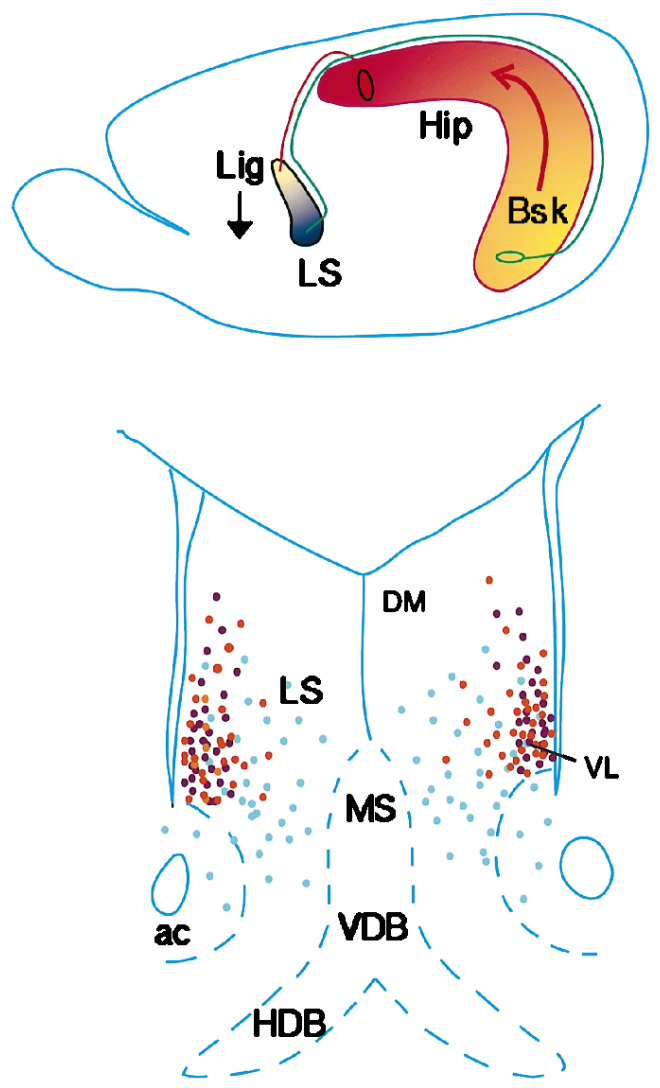

B

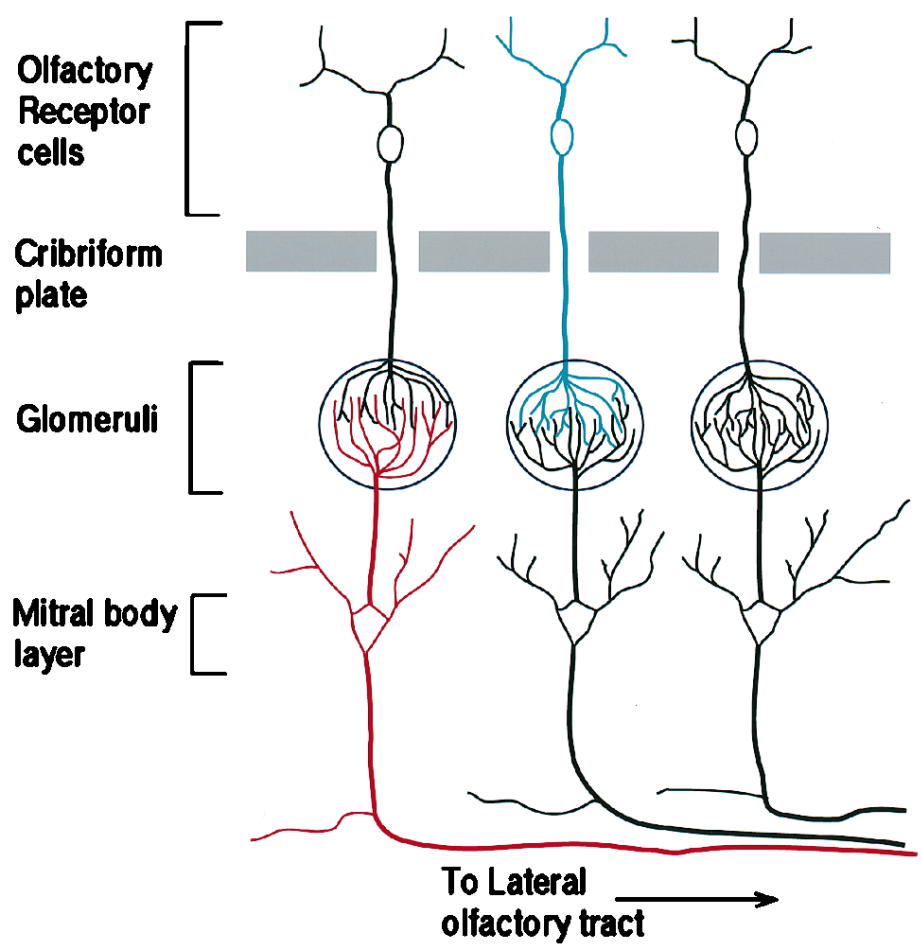

Figure 9. Proposed models for the function of Bsk and its ligands in the hippocamposeptal and olfactory systems. A, The top panel shows that the ligands located in the ventral lateral septum serve to restrict the medial hippocampal neurons (Bsk-positive, red) from innervating this region (ligand-positive, blue), which is topographically inappropriate for the medial neurons. However, the ligands allow the innervation of the ventral lateral septum by the lateral hippocampal neurons, because they lack the receptor Bsk (yellow). The bottom panel shows that three different ligands, Elf-1 (purple), Lerk3 (orange), and AL-1/Lerk7 (light blue) in combination specify a dorsomedial $(D M)$-to-ventrolateral $(V L)$ gradient that may serve as spatial code for hippocamposeptal topographic mapping. $B$, Bsk and its ligand may act to specify different types of synapses between the odor receptor neurons and the mitral or tufted cells. Because the interaction of Eph family ligands and receptors results in inhibition of axonal outgrowth, no synapse may be formed between ligand-positive (blue) odor receptors and Bsk-positive (red) mitral or tufted cells. Thus, only three different types of synapses, ligand-positive odor receptor neurons to Bsk-negative mitral cells (black), ligand-negative odor receptor neurons (black) to Bsk-positive mitral cells, and ligand-negative odor receptor neurons to Bsk-negative mitral cells, are possible. $a c$, Anterior commissure; $D M$, dorsomedial region of the lateral septum; $H D B$, horizontal limb of diagonal band; Hip, hippocampus; Lig, ligand gradient; $L S$, lateral septum; $M S$, medial septum; VDB, vertical limb of diagonal band; $V L$, ventrolateral region of the lateral septum.

\section{Function of Bsk and its ligands in the retinotectal system}

Retinal axons start to invade the superior colliculus around E17E18 in the rat. The axons initially project diffusely over the superior colliculus, making numerous topographically incorrect targeting (Simon and O'Leary, 1992). However, retinal axons branch preferentially in topographically correct locations. In vitro studies indicated that the branching preference of the temporal axons is attributable to inhibitory phosphotidylinositol-linked molecules in the caudal superior colliculus (Roskies and O'Leary, 1994). These molecules are likely to be ligands of the Eph receptor family (Drescher et al., 1995). The adult-like topographic patterns are achieved through axonal branching and arborization at the topographically correct positions and the elimination of mistargeted axons and branches. This process is completed by P11-P12 in rat (Simon and O'Leary, 1992). It is not known when exactly the retinotectal map is established in the mice, but it is likely to be around P6-P7, because the caudal-repulsive activity disappears at P6 (Godement and Bonhoeffer, 1989). Thus, the expression of Elf-1 and AL-1/Lerk7 in the mouse tectum up to P7 is consistent with a role in retinotectal projection.

Our observations confirmed and extended the earlier studies (Cheng et al., 1995; Drescher et al., 1995) by showing that Elf-1 and AL-1/Lerk7 are located in distinct regions of the mouse tectum. Furthermore, we showed that another receptor of the Eph family, Bsk, is also expressed in the retina during the development of retinotectal projection and may play a role in the retinal-tectal interaction. However, Bsk expression in the retina is uniformly distributed, in contrast to the nasal (low)-to-temporal (high) gradient of cek4 transcripts or the dorsal (low)-to-ventral (high) gradient of cek5 (Cheng et al., 1995; Holash and Pasquale, 1995). At least one other Eph family receptor, Sek, is also ex- 
pressed in the retina uniformly (Cheng et al., 1995). Thus, it is likely that Bsk or Sek serves other functions rather than as a surface tag for topographic mapping in this system.

The uniform expression of Bsk and Sek in the retina raises a difficult issue in explaining retinotectal topographic ordering using a model in which the interaction between the Eph ligands and receptors results in inhibition of axonal growth or branching (Cheng et al., 1995; Drescher et al., 1995; Brambilla and Klein, 1996; Friedman and O'Leary, 1996). One would predict that because Bsk and Sek are expressed in the nasal retina, the presence of high levels of Eph ligands in the caudal tectum would prevent nasal axonal targeting to this region. In fact, the growth of nasal axons is indeed inhibited by RAGS in vitro (Drescher et al., 1995). A solution to this paradox may be that the topographic order is achieved by the combined action of Eph family-repulsive cues and other attractive signals. Chemoattractants or trophic factors may be preferentially expressed in the caudal tectum and attract the growth and promote the survival or branching of nasal axons at their correct topographic target. In vitro studies showed that membrane preparations from caudal tectum prolong substantially the survival of nasal neurites (Boxberg et al., 1995), confirming the existence of trophic factors for homing nasal axons. The existence of caudal tectum-specific trophic factors also provides an answer to the question of why nasal axons do not target the rostral tectum. A balance between repulsion and attraction may be critical for the establishment of topographic ordering in both the retinotectal and the hippocamposeptal systems.

In summary, our studies showed that high levels of Bsk and ligands are expressed in complementary patterns in the projecting and target neurons in several neural pathways, suggesting that Bsk and its ligands mediate neuronal targeting in multiple systems.

\section{REFERENCES}

Bartley TD, Hunt RW, Welcher AA, Boyle WJ, Parker VP, Lindberg RA, Lu HS, Colombero AM, Elliott RL, Guthrie BA, Holst PL, Skrine JD, Toso RJ, Zhang M, Fernandez E, Trail G, Varnum B, Yarden Y, Hunter T, Fox GM (1994) B61 is a ligand for the ECK receptor protein-tyrosine kinase. Nature 368:558-560.

Beckmann MP, Cerretti DP, Baum P, Bos TV, James L, Farrah T, Kozlosky C, Hollingsworth T, Shilling H, Maraskovsky C, Fletcher FA, Lhotak V, Pawson T, Lyman SD (1994) Molecular characterization of a family of ligands for Eph-related tyrosine kinase receptors. EMBO J 13:3757-3762.

Bergemann AD, Cheng HJ, Brambilla R, Klein R, Flanagan JG (1995) Elf-2, a new member of the Eph ligand family, is segmentally expressed in mouse embryos in the region of the hindbrain and newly forming somites. Mol Cell Biol 15:4921-4929.

Boxberg YV, Deiss S, Schwarz U (1993) Guidance and topographic stablization of nasal chick retinal axons on target-derived components in vitro. Neuron 10:345-357.

Brambilla R, Klein R (1996) Telling axons where to grow: a role for Eph receptor tyrosine kinases in guidance. Mol Cell Neurosci 6:487-495.

Cerretti DP, Copeland NG, Gilbert DJ, Jenkins NA, Kuefer MU, Valentine V, Shapiro DN, Cui X, Morris SW (1996) The gene encoding LERK-7 (EPLG7, Epl7), a ligand for the eph-related receptor tyrosine kinases, maps to human chromosome 5 at band q21 and the mouse chromosome 17. Genomics 35:376-379.

Cheng H-J, Flanagan JG (1994) Identification and cloning of ELF-1, a developmentally expressed ligand for the Mek4 and Sek receptor tyrosine kinases. Cell 79:157-168.

Cheng H-J, Nakamoto M, Bergemann AD, Flanagan JG (1995) Complementary gradients in expression and binding of ELF-1 and Mek4 in development of the topographic retinotectal projection map. Cell 82:371-381.

Davis S, Gale NW, Aldrich TH, Maisonpierre PC, Lhotak V, Pawson T, Goldfarb M, Yancopoulos G (1994) Ligands for EPH-related receptor tyrosine kinases that require membrane attachment or clustering for activity. Science 266:816-819.

Drescher U, Kremoser C, Handwerker C, Loschinger J, Masaharu N, Bonhoeffer F (1995) In vitro guidance of retinal ganglion cell axons by RAGS, a $25 \mathrm{kDa}$ tectal protein related to ligands for Eph receptor tyrosine kinases. Cell 82:359-370.

Flanagan JG, Leder P (1990) The kit ligand: a cell surface molecule altered in steel mutant fibroblasts. Cell 63:185-194.

Friedman GC, O'Leary DDM (1996) Eph receptor tyrosine kinases and their ligands in neural development. Curr Opin Neurobiol 6:127-133.

Gao P-P, Zhang J-H, Yokoyama M, Racey B, Dreyfus CF, Black IB, Zhou R (1996) Regulation of topographic projection in the brain: Elf-1 in the hippocamposeptal system. Proc Natl Acad Sci USA 93:1116111166.

Godement P, Bonhoeffer F (1989) Cross-species recognition of tectal cues by retinal fibers in vitro. Development 106:313-320.

Graziadei PP (1990) Olfactory development. In: Development of sensory systems in mammals (Coleman JR, ed), pp 616-666. New York: Wiley.

Holash JA, Pasquale EB (1995) Polarized expression of the receptor protein-tyrosine kinase Cek5 in the developing avian visual system. Dev Biol 172:683-693.

Kozlosky CJ, Maraskovsky E, McGrew JT, VandenBos T, Teepe M, Lyman SD, Srinivasan S, Fletcher FA, Gayle III RB, Cerretti DP, Beckmann MP (1995) Ligands for the receptor tyrosine kinases hek and elk: isolation of cDNAs encoding a family of proteins. Oncogene 10:299-306.

Linke R, Pabst T, Frotscher M (1995) Development of the hippocamposeptal projection in the rat. J Comp Neurol 351:602-616.

Malun D, Brunjes PC (1996) Development of olfactory glomeruli: temporal and spatial interactions between olfactory receptor axons and mitral cells in opossums and rats. J Comp Neurol 368:1-16.

Roskies AL, O'Leary DDM (1994) Control of topographic retinal axon branching by inhibitory membrane-bound molecules. Science 265:799-803.

Shao H, Lou L, Pandey A, Pasquale EB, Dixit VM (1994) cDNA cloning and characterization of a ligand for the Cek5 receptor protein-tyrosine kinase. J Biol Chem 269:26606-26609.

Shao H, Lou L, Pandey A, Verderame MF, Siever DA, Dixit VM (1995) cDNA cloning and characterization of a Cek7 receptor protein-tyrosine kinase ligand that is identical to the ligand (ELF-1) for the Mek-4 and Sek receptor protein-tyrosine kinases. J Biol Chem 270:3467-3470.

Shepherd GM (1994) Discrimination of molecular signals by the olfactory receptor neuron. Neurons 13:771-790.

Simon DK, O'Leary DDM (1992a) Development of topographic order in the mammalian retinocollicular projection. J Neurosci 12:1212-1232.

Simon DK, O'Leary DDM (1992b) Responses of retinal axons in vivo and in vitro to position-encoding molecules in the embryonic superior colliculus. Neuron 9:977-989.

Sperry RW (1943) Visuomotor coordination in the newt (Triturus viridescens) after regeneration of the optic nerve. J Comp Neurol 79:33-55.

Sperry RW (1963) Chemoaffinity in the orderly growth of nerve fiber patterns and connections. Proc Natl Acad Sci USA 50:703-710.

Swanson LW (1987) The hypothalamus. In: Handbook of chemical neuroanatomy, Vol 5, Integrated systems of the CNA, Part I (Björklund A, Hökfelt T, Swanson LW, eds), pp 1-124. Amsterdam: Elsevier Science.

Swanson LW, Cowan WM (1975) Hippocampo-hypothalamic connections: origin in subicular cortex, not Ammon's horn. Science 189:303-304.

Swanson LW, Cowan WM (1977) An autoradiographic study of the organization of the efferent connections of the hippocampal formation in the rat. J Comp Neurosci 172:49-84.

Swanson LW, Kohler C, Bjorklund A (1987) The limbic region. I. The septohippocampal system. In: Handbook of chemical neuroanatomy, Vol 5, Integrated systems of the CNA, Part I (Björklund A, Hökfelt T, Swanson LW, eds), pp 124-278. Amsterdam: Elsevier Science.

Winslow JW, Moran P, Valverde J, Shih A, Yuan JQ, Wong SC, Tsai SP, Goddard A, Henzei WJ, Hefti F, Beck KD, Caras IW (1995) Cloning of AL-1, a ligand for an Eph-related tyrosine kinase receptor involved in axon bundle formation. Neuron 14:937-981.

Zhou R, Copeland TD, Kromer LF, Schulz NT (1994) Isolation and Characterization of Bsk, a growth factor receptor-like kinase associated with the limbic system. J Neurosci Res 37:129-143. 